\title{
Diode laser photocoagulation for diabetic macular oedema
}

\author{
Michael W Ulbig, Dominic A McHugh, A M Peter Hamilton
}

\begin{abstract}
Aims-This study aimed to investigate whether diode laser irradiation, which is poorly absorbed by haemoglobin, can induce closure of leaking retinal microvascular lesions in the treatment of diabetic macular oedema.

Methods-Thirty three eyes with clinically significant diabetic macular oedema were treated with a diode laser. Fundus evaluation before and after treatment included visual acuity, stereoscopic biomicroscopy, colour photographs, and fluorescein angiography.

Results-At a mean period of review of 6 months macular oedema had completely or partially resolved in 27 eyes. Visual acuity improved in three, deteriorated in one, and was unchanged in 29 eyes.

Conclusion-Preliminary data suggest that diode laser therapy induces closure of leaking retinal microaneurysms and is effective in the treatment of diabetic macular oedema.
\end{abstract}

(Br f Ophthalmol 1995; 79: 318-321)

Retinal Diagnostic

Department,

Moorfields Eye

Hospital, London

$M$ W Ulbig

D A McHugh

A M P Hamilton

Correspondence to: Michael W Ulbig, MD, Moorfields Eye Hospital, City Road, London EC1V 2PD.

Accepted for publication 9 December 1994

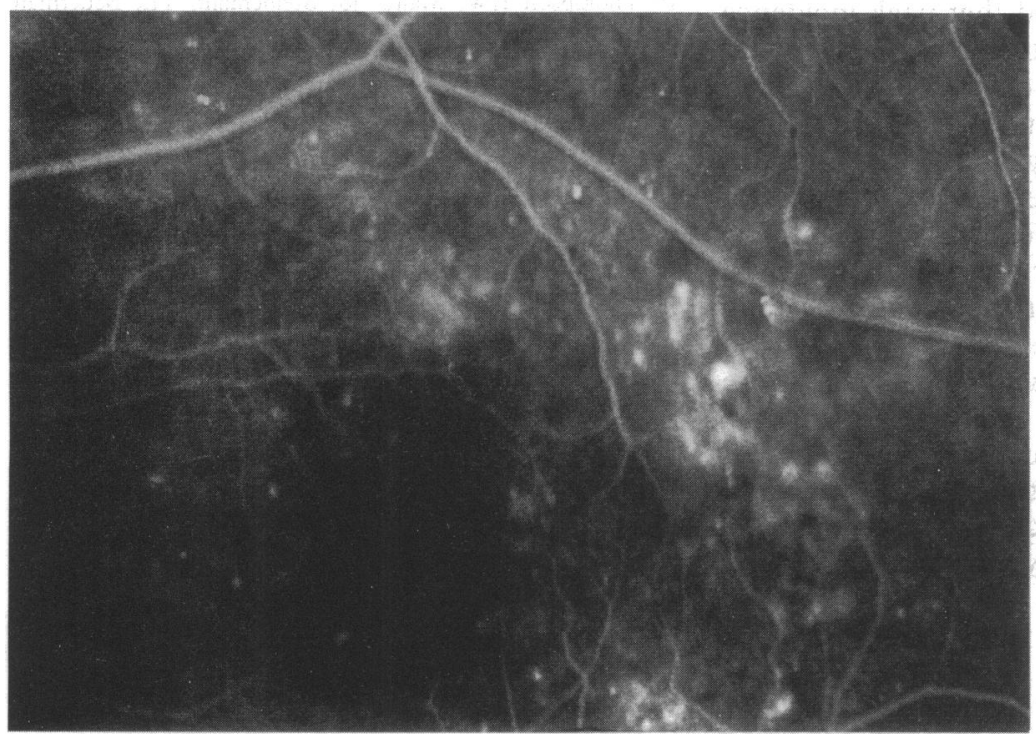

Figure $1 A$ Fluorescein angiogram showing leaking retinal microaneurysms located in close proximity to the fovea.

Diode lasers have a number of advantages over other laser systems. There are no requirements for either an ancillary cooling system or a three phase electricity supply. In addition, they are more compact, portable, cheaper to maintain, and have a long operating life. ${ }^{1}$ Histological studies have established that irradiation of retinal tissue with a diode laser (wavelength $810 \mathrm{~nm}$, near infrared) results in sufficient absorption within melanin of the retinal pigment epithelium to induce a clinically significant burn. ${ }^{2}$ Pilot clinical trials subsequently established the efficacy of diode laser panretinal photocoagulation in the treatment of proliferative diabetic retinopathy, ${ }^{3-5}$ and recently it was demonstrated that panretinal diode laser treatment probably causes less functional loss than argon laser photocoagulation. ${ }^{6}$

The Early Treatment Diabetic Retinopathy Study Group (ETDRS $)^{7}$ has proved that focal argon laser treatment (514 $\mathrm{nm}$ ) is effective in the treatment of diabetic macular oedema. The generally believed underlying mechanism of action is absorption of green laser light by haemoglobin within retinal microaneurysms. However, diode laser near infrared radiation at $810 \mathrm{~nm}$ is not significantly absorbed by haemoglobin. ${ }^{8}$ Thus, direct ablation of leaking retinal vasculature using a diode laser may be impossible. On the other hand the absence of absorption within the macular luteal pigment suggests the near infrared diode system as an ideal laser for macular disorders. ${ }^{8-13} \mathrm{~A}$ prospective pilot study was performed to evaluate the effects of diode laser treatment on diabetic macular oedema, and also to attempt to gain further insight into possible mechanisms of action.

\section{Patients and methods}

Twenty five consecutive diabetic patients (33 eyes) referred to the retinal diagnostic department at Moorfields Eye Hospital for laser therapy of clinically significant diabetic macular oedema, in line with the ETDRS definition, ${ }^{7}$ were recruited for focal photocoagulation with the 'Microlase' diode laser (Keeler, Windsor), emitting at $810 \mathrm{~nm}$. The laser was attached to a slit-lamp microscope (Haag Streit 900, Bern, Switzerland). The patients ranged in age from 30 to 77 (mean age 56) years. Nine patients were female and 16 male. Seven patients had type I and 18 type II diabetes mellitus. The known duration of diabetes ranged from 1 to 32 (mean duration 11) years. Before entry into the study the patients had to provide informed consent.

Fundus evaluation before and after treatment consisted of best corrected visual acuity, stereoscopic biomicroscopy, colour fundus photographs, and intravenous fluorescein angiography. Visual acuity measurements were standardised and always independently performed by a trained nurse in the same examination room with identical illumination of the Snellen chart and background. A change of two lines on the Snellen chart was taken to denote a significant decrease or increase in visual acuity. The period of review ranged from 


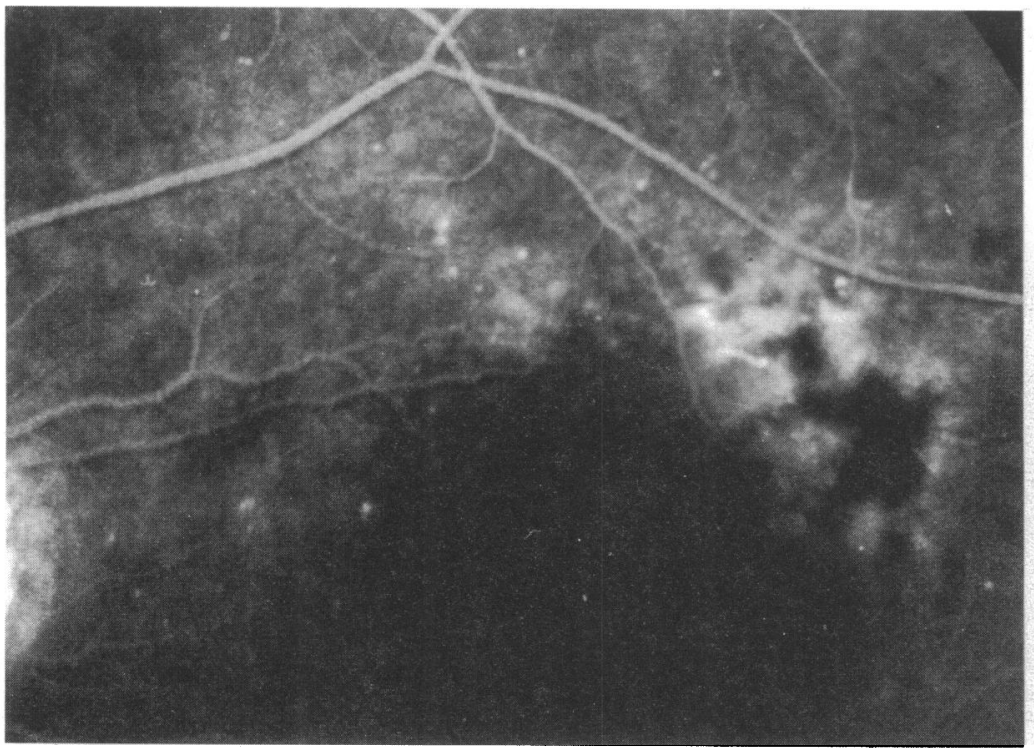

Figure 1B Fluorescein angiogram of the same eye as in Figure 1A, here 3 months after focal diode laser photocoagulation to the retinal pigment epithelium underlying the microaneurysms. The microaneurysms do not stain any more.

3 to 15 months, with a mean of 6 months. The clinical review was performed every 3 months.

After mydriasis with tropicamide $1 \%$ (Mydracil) and topical anaesthesia with benoxinate $0.4 \%$ eyedrops, an area centralis contact lens (Volk, USA) was applied. Treatment variables were a spot size of $100 \mu \mathrm{m}$, exposure duration of 0.4 seconds, and powers

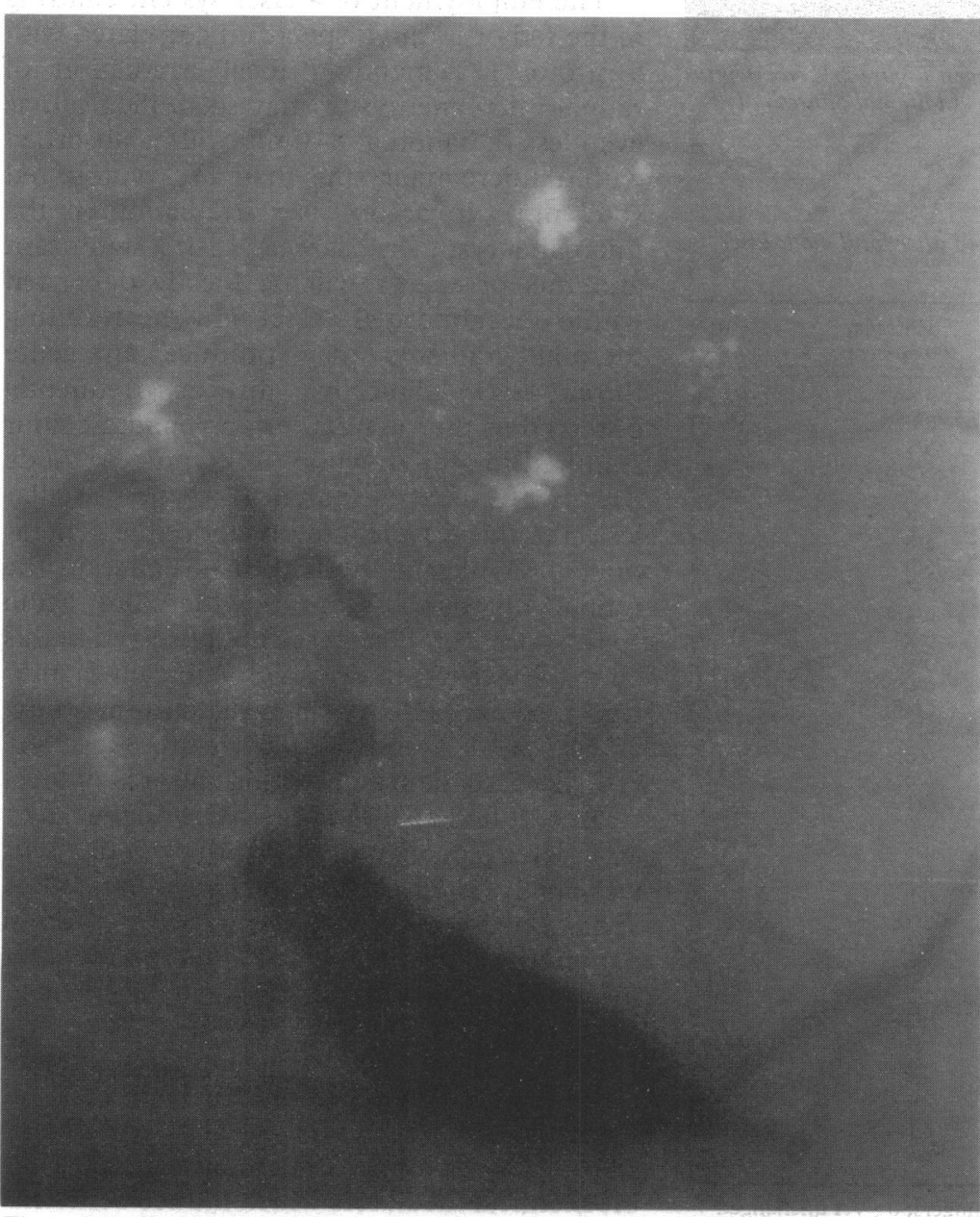

Figure $2 A$ Fundus photograph of the right macula showing clinically significant macular oedema with hard exudates and a subhyaloid haemorrhage caused by additional proliferation. between 200 and $1000 \mathrm{~mW}$ (mean $560 \mathrm{~mW}$ ). The desired endpoint was to produce a threshold burn, with mild blanching of the retinal pigment epithelium, either focally deep to the leaking microaneurysm, or in a grid pattern in thickened retina within a circinate ring of hard exudate. In eyes with additional proliferative diabetic retinopathy the macular oedema was treated first and panretinal diode laser photocoagulation was performed when the macular oedema showed resolution.

After treatment the patients had to complete a questionnaire relating to adverse symptoms experienced during therapy.

\section{Results}

During the review period of this study, it was observed that in 27 of 33 eyes treated, there was complete or partial resolution of biomicroscopically visible retinal thickening, and the disappearance of 'treated' leaking microaneurysms on fluorescein angiography (Fig 1). Although there was no evidence of any acute laser induced effect on the microvascular lesions in the sensory retina, closure was observed to occur over a time course of 3 months, with attendent reduction in retinal oedema and the density of hard exudates (Fig 2). Visual acuity improved in three, deteriorated in one, and was unchanged in 29 eyes (Table 1). From seven to 236 (mean 78) diode laser exposures per eye were required, depending on the severity of the maculopathy that is, the degree and extension of retinal thickening and the number of retinal microaneurysms. Eight eyes required repetition of diode laser photocoagulation at the 3 month follow up and three of these eyes showed a beneficial effect at the following appointment. Two eyes had additional panretinal treatment for developing proliferative diabetic retinopathy.

As a consequence of the near infrared treatment beam, no patient noticed any bright flashes during therapy. Also, no pain was noticed during macular treatments. In no case was it necessary to abandon therapy, or to perform retrobulbar or peribulbar anaesthesia. The absence of discomfort ensured that the patient remained perfectly still during therapy and this enhanced the precision of retinal targeting. The penetration of infrared diode laser light through macular oedema was excellent.

\section{Discussion}

This initial pilot study shows that focal treatment with a near infrared laser beam was effective in the treatment of focal diabetic macular oedema. The majority of eyes included had very good visual acuity at entry level which was severely threatened by clinically significant macular oedema. Overall, there was very little loss in visual acuity over the period of review. Reabsorption and improvement of retinal thickening and hard exudates occurred in 27 out of 33 eyes treated focally with the diode laser. It may be argued that the follow up 




Figure $2 B$ Fundus photograph of the right macula, same eye as in Figure $2 A$. Six month after focal diode laser treatment the hard exudates are less dense. Additional panretinal treatment was performed 3 months after focal photocoagulation.

Table 1 Visual acuity before and after focal diode laser photocoagulation

\begin{tabular}{|c|c|c|c|c|c|}
\hline $\begin{array}{l}\text { Patient } \\
\text { No }\end{array}$ & $\begin{array}{l}\text { Eye } \\
R / L\end{array}$ & No & $\begin{array}{l}V A \text { before } \\
\text { treatment }\end{array}$ & $\begin{array}{l}V A \text { at } \\
\text { last vis }\end{array}$ & \\
\hline 1 & $\mathbf{R}$ & 1 & $6 / 60$ & $6 / 36$ & 0 \\
\hline 1 & $\mathrm{~L}$ & 2 & $6 / 60$ & $6 / 36$ & 0 \\
\hline 2 & $\mathbf{R}$ & 3 & $6 / 5$ & $6 / 6$ & 0 \\
\hline 3 & L & 4 & $6 / 36$ & CF & - \\
\hline 4 & $\mathrm{~L}$ & 5 & $6 / 6$ & $6 / 9$ & 0 \\
\hline 5 & $\mathbf{R}$ & 6 & $6 / 9$ & $6 / 9$ & 0 \\
\hline 6 & $\mathbf{R}$ & 7 & $6 / 6$ & $6 / 9$ & 0 \\
\hline 6 & L & 8 & $6 / 9$ & $6 / 9$ & 0 \\
\hline 7 & L & 9 & $6 / 6$ & $6 / 6$ & 0 \\
\hline 8 & $\mathbf{R}$ & 10 & $6 / 18$ & $6 / 9$ & + \\
\hline 8 & $\mathrm{~L}$ & 11 & $6 / 24$ & $6 / 18$ & 0 \\
\hline 9 & $\mathbf{R}$ & 12 & $6 / 9$ & $6 / 9$ & 0 \\
\hline 10 & $\mathbf{R}$ & 13 & $6 / 60$ & $6 / 60$ & 0 \\
\hline 10 & L & 14 & $6 / 36$ & $6 / 36$ & 0 \\
\hline 11 & $\mathbf{R}$ & 15 & $6 / 9$ & $6 / 9$ & 0 \\
\hline 12 & $\mathbf{R}$ & 16 & $6 / 6$ & $6 / 6$ & 0 \\
\hline 12 & L & 17 & $6 / 6$ & $6 / 6$ & 0 \\
\hline 13 & $\mathrm{~L}$ & 18 & $6 / 12$ & $6 / 12$ & 0 \\
\hline 14 & $\mathbf{R}$ & 19 & $6 / 9$ & $6 / 5$ & + \\
\hline 15 & $\mathbf{R}$ & 20 & $6 / 5$ & $6 / 5$ & 0 \\
\hline 16 & $\mathbf{R}$ & 21 & $6 / 9$ & $6 / 12$ & 0 \\
\hline 16 & $\mathrm{~L}$ & 22 & $6 / 6$ & $6 / 9$ & 0 \\
\hline 17 & L & 23 & $6 / 18$ & $6 / 18$ & 0 \\
\hline 18 & $\mathbf{R}$ & 24 & $6 / 6$ & $6 / 9$ & 0 \\
\hline 18 & $\mathrm{~L}$ & 25 & $6 / 9$ & $6 / 9$ & 0 \\
\hline 19 & $\mathbf{R}$ & 26 & $6 / 9$ & $6 / 9$ & 0 \\
\hline 20 & $\mathbf{R}$ & 27 & $6 / 12$ & $6 / 9$ & 0 \\
\hline 21 & $\mathbf{R}$ & 28 & $6 / 18$ & $6 / 12$ & 0 \\
\hline 22 & L & 29 & $6 / 6$ & $6 / 6$ & 0 \\
\hline 23 & $\mathbf{R}$ & 30 & $6 / 9$ & $6 / 9$ & 0 \\
\hline 24 & $\mathbf{R}$ & 31 & $6 / 6$ & $6 / 6$ & 0 \\
\hline 24 & L & 32 & $6 / 6$ & $6 / 6$ & 0 \\
\hline 25 & $\mathbf{R}$ & 33 & $6 / 9$ & $6 / 5$ & + \\
\hline
\end{tabular}

$\mathrm{VA}=$ visual acuity $\mathrm{CF}=$ counting fingers; $0=\mathrm{VA}$ unchanged (change less than 2 lines on Snellen chart); $+=$ VA improved by 2 lines on Snellen chart; $-=$ VA deteriorated by 2 lines on Snellen chart. period of this pilot study was rather short; however, a follow up of 4 months is generally considered sufficient after argon laser treatment for macular oedema. Moreover, there is no untreated control group in our initial pilot study. However, the well accepted ETDRS studies ${ }^{7}$ have shown in their initial report that diabetic eyes with clinically significant oedema are at a very high risk of losing vision within 12 months. Owing to this observation it was found unacceptable to preclude such eyes from effective focal laser treatment and the study design was altered immediately to cover this. Thus we thought that creating a control group of untreated eyes in our initial pilot study would not comply with ethical standards.

Diabetes mellitus may affect the macula in a number of ways. Ischaemic maculopathy is not amenable to treatment, but oedematous diabetic maculopathy has been shown to benefit from focal or grid photocoagulation. The efficacy of argon laser treatment for such maculopathy has been confirmed by the results of several studies. ${ }^{714}$

Currently, the preferred technique for laser treatment of clinically significant diabetic macular oedema is to focally irradiate leaking retinal microaneurysms with argon laser radiation. The underlying concept in such photocoagulation treatment is that closure of these discrete sources of leakage results in eventual resorption of hard exudates and resolution of retinal thickening.

The employment of a laser system emitting in the red or infrared spectrum correlated with a protocol demanding focal irradiation of retinal microaneurysms may seem illogical, as even less radiation at $810 \mathrm{~nm}$ will be absorbed within microaneurysms than at krypton red $(647 \mathrm{~nm})$. In argon laser irradiation, if the microaneurysm is large, then significant amounts of energy will be focally deposited within the abnormal vessel and the resulting thermal gradients may produce an acute thrombosis. Clinically, this is frequently observed as the vascular lesion changes colour from red to greyish white. In krypton or diode treatment, the transparency of the vascular lesion to this wavelength precludes the generation of significant thermal disturbance in the retinal microaneurysm and therefore acute spasms or thrombosis were not observed in this study. However, in eyes with clinically significant macular oedema, as in the current study, at review 3 months after treatment, many retinal microaneurysms within the area of focal treatment had resolved together with partial or complete resorption of retinal thickening. This was finally observed in 27 of 33 eyes treated. A similar clinical response has been reported in patients treated with a krypton or dye-red laser in a grid pattern for diffuse diabetic macular oedema. ${ }^{15} 16$

Laboratory studies employing tissue culture techniques on both human retinal pigment epithelial cells and retinal capillary endothelial cells are beginning to demonstrate possible biochemical mediators which induce beneficial tissue responses secondary to photocoagulation. ${ }^{17} 18$ Such permeable factors may be 
relatively acute such as relating to opening of the blood-retinal barrier or death of pigment epithelial cells, ${ }^{19}$ or may be somewhat delayed and depend upon a body of pigment epithelial cells proliferating. ${ }^{20}$ In the former case, newly proliferated capillary endothelial cells may result in retinal vessels with a lower permeability and therefore less leakage of plasma constituents, while in the latter the newly formed retinal pigment epithelial cells may increase the removal of fluid from the retina.

Proliferating retinal pigment epithelial cells have also been shown to be correlated with the presence of factors in the vitreous which are seen to inhibit retinal vascular endothelial cell division in vitro and may play a role in the effect of panretinal photocoagulation. ${ }^{1820} \mathrm{It}$ therefore seems that much of the beneficial effect of photocoagulation in retinal vascular disease derives from processes dependent on energy deposition in the retinal pigment epithelium rather than in retinal vessels themselves. Even in direct ablation of a retinal micronaneurysm using the argon green laser there is a considerable 'spillover' of energy onto the retinal pigment epithelium which may be beneficial. If this is the case, then the match of emission wavelength of clinical lasers in relation to the haemoglobin absorption spectra is relatively unimportant.

A clinicopathological study tends to confirm the concept that closure of retinal microaneurysms is not due to direct absorption of laser energy within the lesion. Wallow and Bindley performed histological examination on a human retina that had been given focal photocoagulation for diabetic macular oedema. It was found that the majority of retinal burns involved the retinal pigment epithelium and photoreceptor layer. In all but a few heavy burns, there was sparing of the inner nuclear layer, within which microaneurysms tend to be located. It was observed, however, the focal photocoagulation had resulted in successful closure of many of the microvascular lesions. ${ }^{21}$ It therefore appears to be likely that the current protocol in relation to focal macular photocoagulation demands power levels in excess of those necessary to produce the desired therapeutic effect.

In conclusion, photocoagulation with near infrared wavelength may have a number of biophysical advantages over treatment with laser radiation of shorter wavelengths. There is better transmission through media opacities for example, nuclear sclerotic cataracts, and during treatment the patient is not irritated by bright flashes. In macular treatment there is no extra pain compared with the argon laser. ${ }^{322}$
By historical comparison, in this initial pilot study the diode laser was equally effective in the treatment of clinically significant diabetic macular oedema as the established argon laser system.

This study was supported by the European Science Exchange Pros Programme, grant no 623008.F621/DJHG/LM the Royal Society, London, United Kingdom, and grant no U1
Deutsche Forschungsgemeinschaft, Bonn, Germany.

1 Brancato R, Patresi R, Leoni G, Trabucchi G, Giovannoni $L$, Vanni U. Retinal photocoagulation with diode laser operating from a slitlamp microscope. Lasers Light Ophthalmol 1988; 2: 73-8.

2 McHugh JDA, Marshall J, Capon M, Rothery S, Raven A, Naylor RP. Transpupillary retinal photocoagulation in the eyes of rabbit and human using a diode laser. Lasers Light Ophthalmol 1988; 2: 125-43.

3 Ulbig MW, Hamilton AMP. Vergleichende Anwendung von Argon-und Diodenlaser zur panretinalen Photokoagulation bei diabetischer Retinopathie. Ophthalmologe 1993; 90: 457-62.

4 McHugh JDA, Marshall J, ffytche TJ, Hamilton AM, Raven $A$, Keeler CR. Initial clinical experience using a diode laser in the treatment of retinal vascular disease. Eye 1989; 3: 516-27.

5 Bandello F, Brancato R, Trabucchi G, Lattanzio R, Malegori A. Diode versus argon-green laser panretinal photocoagulation in proliferative diabetic retinopathy: a photocoagulation in proliferative diabetic retinopathy: a Graefes Arch Clin Exp Ophthalmol 1993; 231: 491-4.

6 Ulbig MW, Arden GB, Hamilton AMP. Color contrast sensitivity and pattern electroretinographic findings after diode and argon laser photocoagulation in diabetic retinopathy. Am F Ophthalmol 1994; 117: 583-8.

7 Early Treatment Diabetic Retinopathy Study Group. Ophthalmology 1991; 98 (suppl 5): 739-840.

8 McHugh JDA, Marshall J, ffytche TJ, Hamilton AM, Raven A. Macular photocoagulation of human retina with a diode laser: a comparative histopathological study. Lasers Light Ophthalmol 1990; 3: 11-28.

9 Gabel VP, Birngruber R, Hillenkamp F. Visible and near infra-red light absorption in pigment epithelium and choroid. In: Acta XXIII Concilium Ophthalmologicum (Kyoto) 1978; 1: 658-62.

10 Wallow IHL, Sponsel WE, Stevens TS. Clinicopathologic correlation of diode laser burns in monkeys. Arch Ophthalmol 1991; 109: 648-53.

11 Marshall J, Bird AC. A comparative histopathological study of argon and krypton laser irradiations of the human retina. Br $\mathcal{f}$ Ophthalmol 1979; 63: 657-68.

12 Ulbig MW, McHugh JDA, Hamilton AMP. Photocoagulation of choroidal neovascular lesions with a diode laser. Br f Ophthalmol 1993; 77: 218-21.

13 Mainster MA. Wavelength selection in macular photocoagulation: tissue optics, thermal effects, and laser systems. Ophthalmology 1986; 93: 952-8.

14 Resser F, Fleischmann J, Williams GA, Goldmann A Efficacy of argon laser photocoagulation in the treatment of circinate diabetic retinopathy. Am $\mathcal{F}$ Ophthalmol 1981; 92: 762-7.

15 Olk RJ. Argon-green ( $514 \mathrm{~nm})$ versus krypton red (647 nm) modified grid laser photocoagulation for diffuse diabetic macular edema. Ophthalmology 1990; 97: 1101-13.

16 Freyler $H$. Lasertherapie bei diabetischer Makulopathie. Eine Vergleichsstudie zwischen Argoni-grün und Dye-rotLaser. Klin Monatsbl Augenheilkd 1990; 197: 176-81.

17 Glaser BM, D'Amore PA, Michels RG. Demonstration of vasoproliferative activity from mammalian retina. $\mathcal{f}$ Cell Biol 1980; 84: 298-304.

18 Glaser BM, Campochiaro PA, Davis JL, Sato M. Retinal pigment epithelial cells release an inhibitor of neovascularization. arch Ophthalmol 1985; 103: 1870-5.

19 Glaser BM. Extracellular modulating factors and the control of intraocular neovascularization: an overview. Arch Ophthalmol 1988; 106: 603-7.

20 Marshall J, Clover G, Rothery S. Some new findings on retinal irradiation by krypton and argon lasers. Doc Ophthalmol Proc Ser 1984; 36: 21-37.

21 Wallow IHL, Bindley CD. Focal photocoagulation of diabetic macular edema. Retina 1988; 8: 261-9.

22 Gabel VP, Lorenz B, Obana A, Vogel A, Birngruber R. Problems of clinical application of diode lasers. Lasers Light Ophthalmol 1992; 4: 157-63. 